\title{
Identifying Dysphagia and Demographic Associations in Older Adults Using Electronic Health Records: A National Longitudinal Observational Study in Wales (United Kingdom) 2008-2018
}

\author{
Joe Hollinghurst ${ }^{1} \cdot$ David G. Smithard ${ }^{2,3}$ \\ Received: 26 July 2021 / Accepted: 14 February 2022 / Published online: 25 February 2022 \\ (c) The Author(s) 2022
}

\begin{abstract}
Dysphagia is increasingly being recognised as a geriatric syndrome (giant). There is limited research on the prevalence of dysphagia using electronic health records. To investigate associations between dysphagia, as recorded in electronic health records and age, frailty using the electronic frailty index, gender and deprivation (Welsh index of multiple deprivation). A Cross-sectional longitudinal cohort study in over 400,000 older adults was undertaken (65+) in Wales (United Kingdom) per year from 2008 to 2018. We used the secure anonymised information linkage databank to identify dysphagia diagnoses in primary and secondary care. We used chi-squared tests and multivariate logistic regression to investigate associations between dysphagia diagnosis and age, frailty (using the electronic Frailty index), gender and deprivation. Data indicated $<1 \%$ of individuals were recorded as having a dysphagia diagnosis per year. We found dysphagia to be statistically significantly associated with older age, more severe frailty and individuals from more deprived areas. Multivariate analyses indicated increased odds ratios [OR (95\% confidence intervals)] for a dysphagia diagnosis with increased age [reference 65-74: aged 75-84 OR $1.09(1.07,1.12), 85$ + OR $1.23(1.20,1.27)]$, frailty (reference fit: mild frailty $2.45(2.38,2.53)$, moderate frailty $4.64(4.49,4.79)$ and severe frailty $7.87(7.55,8.21)]$ and individuals from most deprived areas [reference 5. Least deprived, 1. Most deprived: $1.10(1.06,1.14)]$. The study has identified that prevalence of diagnosed dysphagia is lower than previously reported. This study has confirmed the association of dysphagia with increasing age and frailty. A previously unreported association with deprivation has been identified. Deprivation is a multifactorial problem that is known to affect health outcomes, and the association with dysphagia should not be a surprise. Research in to this relationship is indicated.
\end{abstract}

Keywords Frailty $\cdot$ Old age $\cdot$ Dysphagia $\cdot$ Prevalence $\cdot$ Epidemiology $\cdot$ Deprivation

\section{Introduction}

\section{Background}

Older people are a becoming a larger percentage of the world's population, with $15 \%$ of the UK population aged

David G. Smithard

david.smithard@nhs.net

Joe Hollinghurst

j.p.hollinghurst@swansea.ac.uk

1 Swansea University, Singleton Park, Sketty, Swansea SA2 8PP, UK

2 Queen Elizabeth Hospital, Lewisham and Greenwich NHS Trust, Stadium Road, Woolwich, London SE18 4QH, UK

3 University of Greenwich, Avery Hill Campus, Bexley Rd, London SE9 2PQ, UK 65 years and over $[1,2]$. In the UK demography, the $85+$ age group (very old) is the fastest growing cohort and is estimated to double to 3.2 million by mid-2041 and treble by 2066 (5.1 million; 7\% of the UK population) [3-6]. More concerning is that over the last 15 years, there has been an $85 \%$ increase in the number of centenarians, which is predicted to reach 21,000 by 2030 [6].

Swallowing is a complex interplay of the cerebral cortex and brainstem, several cranial nerves and multiple muscles in the head and neck [7]. The main purpose of swallowing is to transfer food safely from the mouth to the stomach 
whilst protecting the airway. There are three sequential phases of swallowing: oral, pharyngeal and oesophageal. The pharyngeal swallow is semi-automatic and occurs in a coordinated sequence, the timings of which will be modulated by the cortex depending on the characteristics of the bolus/food swallowed [8]. Dysfunction (secondary to localised or generalised disease processes) in one or more of the phases may result in dysphagia (difficulty swallowing) [9, 10]. Dysphagia is defined as a subjective sensation of difficulty or abnormality of swallowing [11]. This definition encompasses oropharyngeal dysphagia, oesophageal dysphagia and reflux disease.

Changes to eating and swallowing may occur with age, with some individuals accepting this as a normal part of ageing, slowly adapting the quantity and texture of food eaten and the time taken to eat, often referred to as presbyphagia $[11,12]$. Physiological changes to the swallow with increasing age may vary with gender and between individuals. In general, it has been found that there is reduced hyoid excursion, laryngeal elevation and anterior rotation in individuals with dysphagia. Transit times through the pharynx increase, and UES opening is prolonged [13]. When does a change in swallow pattern become pathological? Humbert and Robbins [14] cautioned against labelling a "normal yet safe swallow" as being evidence of dysphagia. McCullough et al. comment that laryngeal penetration was more frequent and deeper in the older age group, but that clearance was the usual outcome [15]. Presbyphagia [11] is defined as "characteristic changes in the mechanism of oropharyngeal/oesophageal swallowing of otherwise healthy older adults" which may manifest as fatigue [16] and slowness of eating rather than overt dysphagia. The identified physiological changes with age $[17,18]$ may be directly or indirectly secondary to frailty and pre-existing comorbidities, rather than age specific.

There have been many prevalence/epidemiological studies of dysphagia in community living older people [15, 19-26]. These surveys have been completed over three decades and have used several different methodologies including postal surveys, cold-calling telephone calls and clinic waiting room approaches. The studies have also used variable definitions of "old" and of what constitutes dysphagia [27], which makes comparisons difficult.

Determining/understanding the prevalence of dysphagia in the community is complex. Studies are referenced to a particular country, set environment or disease state, rather than an unselected population. Often the definition of dysphagia is vague or not stated. The true prevalence of dysphagia in the community is uncertain, with a wide range from 2.5 to $72 \%$ [17, 25, 27-32] reported. Adkins et al. reported a prevalence of $16.1 \%$ (4998/31129) across all age groups [20], whereas Battacharyya reported a $4 \%$ prevalence from a cohort of 30,000 in a household survey [33]. Kertscher et al. using EAT-10 as part of a telephone survey, found that
$21.9 \%$ of those $>76$ years scored $\geq 3$, indicating problems swallowing [21]. A study by Andersen et al. found that $26 \%$ of participants reported difficulty taking tablets [34]. In two studies of community living older ( $>65$ years) adults, at different time points [35, 36], 33.7\% of those in Korea were found to have symptoms of dysphagia, whilst the prevalence was only $13.8 \%$ in Japan. Patel et al. reported that $3.1 \%$ of all adult admissions to hospital had a diagnosis of dysphagia [37].

Frailty is a modern geriatric syndrome (giant) [38], but identifying frailty can be difficult due to the lack of a universally accepted definition [18]. Frailty has been defined by some as "a biologic disorder affecting many activities of daily living characterised by diminishing physiological reserves $[39,40]$ which may be due to an accumulation of multiple system deficits" [41], and as a "state of reduced strength and physiological malfunctioning that increases a person's susceptibility to increased dependency, vulnerability and even death" [42, 43]. It is generally accepted that the prevalence of frailty increases with age, with approximately $25-50 \%$ of people over the age of 85 years being frail [44]. In hospital populations, studies have shown that frailty and dysphagia frequently co-exist $[14,45,46]$ but there remains a debate as to whether there is a distinct entity of frailty dysphagia [14]. Recent papers [38, 47] define oral frailtybut not frailty dysphagia—as a decrease in oral functioning together with a decline in cognitive and physical function but fail to fully develop the discussion. Tanaka et al. noted that poor oral status in $\geq 1$ oral domain was a predictor for physical frailty, suggesting association rather than a distinct entity of oral frailty. However, it is to be expected that dysphagia co-exists with frailty due to the suprahyoid muscle complex and the masseter muscle being skeletal in nature [48].

Frail older adults admitted to hospital have a prevalence of dysphagia of $55 \%[14,45]$. Cha et al. report that sarcopenia and dysphagia are concurrent in $6 \%$ of community dwelling older adults ( $>65$ years) [49]. Hansen et al. found that at a follow-up assessment of 56 weeks after discharge from hospital, $25 \%$ of older adults had dysphagia and that there was a significant relationship at the $p<0.05$ level with sarcopenia, low physical performance and malnutrition [50]. These changes, combined with changes to food preferences, have the potential to result in under-nutrition [18]. These inter-relationships contribute to a "failure to thrive" and have the potential to accelerate people towards a terminal physical decline ultimately resulting in death.

Nursing home populations have a greater prevalence due to many residents having a diagnosis of dementia, stroke or Parkinson's disease alone, or in combination, with frailty $[51,52]$. In a systematic review by Takizawa et al., dysphagia was diagnosed in $8.1-80 \%$ of stroke patients, $27-30 \%$ of brain injury patients, $11-81 \%$ of Parkinson disease patients and $91.7 \%$ of older persons with community-acquired 
pneumonia due to impaired swallowing and breathing mechanisms [53].

In the clinical situation, despite clinical staff being aware that dysphagia is a complication of many aetiological mechanisms, including mechanical, neurological and psychological [54], it is nevertheless often under-diagnosed and undertreated [55]; as a consequence, there is an increased risk of malnutrition, dehydration, pneumonia [56] and mortality [57] in the relevant populations.

\section{Rationale for the Study}

Studies may over or under report the prevalence of dysphagia in the community depending on the research approach taken. Bias may be introduced by both the survey and the researcher. Those studies of dysphagia focussing on older people have tended to be small $[17,26]$, and larger studies have relied on census data [24, 33]. No studies have examined the medical data held in electronic health records (EHRs) that have been collated as part of day-to-day clinical care and explored the relationship with and age, gender, frailty and deprivation.

The use of existing anonymised routinely collected longitudinal data can help provide rapid access to large-scale data for studies and provide robust evidence for commissioning decisions and policy $[58,59]$. In this study, we utilise the Secure Anonymised Information Linkage (SAIL) Databank [60-62] to investigate the recording of dysphagia in EHRs in older adults in Wales over time. We also include linked data to explore associations between dysphagia and age, gender, frailty and deprivation.

\section{Methods}

\section{Study Design}

We used anonymised EHRs and administrative data from the SAIL Databank to create a longitudinal cross-sectional cohort study.

For the purposes of this study, we have accepted dysphagia as any entry in to the EHR that documents dysphagia or swallowing problem/difficulty.

\section{Data Sources}

Our cohorts were created using data held within the SAIL Databank [60-62]. The SAIL Databank contains longitudinal anonymised administrative and healthcare records for the population of Wales. The anonymisation is performed by a trusted third party, the National Health Service Wales Informatics Service. The SAIL Databank has a unique individual anonymised person identifier known as an anonymous linking field and a unique address anonymised identifier known as a residential anonymous linking field [63] that are used to link between data sources at individual and residential levels, respectively. Individual linking fields, nested within residential codes, are contained in the anonymised version of the Welsh Demographic Service Dataset (WDSD), replacing the identifiable names and addresses of people registered with a free-to-use General Practitioner service.

The WDSD contains demographic information including week of birth, gender, date of death and lower-layer super output area (LSOA). Each LSOA in Wales has been ranked from most deprived to least deprived according to the Welsh Index of Multiple Deprivation (WIMD), an area-based measure of socio-economic status [64]. We used the 2011 version of LSOA linked to the 2014 version of the WIMD and used deprivation quintiles in the analyses. To detect dysphagia in older adults, we used both the Welsh Longitudinal General Practice (WLGP) dataset and the Patient Episode Database for Wales (PEDW). The WLGP contains general practice data for approximately $80 \%$ of the population of Wales, and we used Read codes version 2 (CTV2) to identify dysphagia. The PEDW dataset contains all hospital admission records in Wales, and we identified individuals with dysphagia in these records using the international classification of disease version 10 (ICD-10) code for dysphagia.

\section{Setting and Participants}

We included all individuals aged $65+$ living in Wales with a valid address who were registered with a general practice contributing data to the SAIL databank. We created 11 cohorts independently, one for each year from 2008 to 2018. Dysphagia was identified in the previous year from the cohort index dates to mitigate the need for censoring due to death or migration. For example, the cohort created for 2008 had index date 1st January 2008, and dysphagia was identified from 1st January 2007 to 31st December 2007.

\section{Variables}

Our outcome of interest was dysphagia identified in either general practice or hospital records. We used CTV2 Read codes to identify dysphagia in general practice records and ICD-10 codes to identify dysphagia in hospital records. We created binary indicators for dysphagia for each person, each year if dysphagia was identified in either general practice, hospital records, or both in the year prior to the cohort index date. No restriction was placed on the number of codes searched in either general practice or hospital records. The cohort index dates were treated as categorical and included as the year of the cohort index date (2008 to 2018). Age was calculated on the cohort index date and was categorised in 
to three groups: $65-74,75-84,85+$. Gender (male/female) was treated as categorical variable. Frailty was calculated using the electronic Frailty index (eFI). The eFI is based on an internationally established cumulative deficit model and assigns a frailty score to an individual calculated using 36 variables from primary care GP data, including symptoms, signs, diseases, disabilities and abnormal laboratory values, referred to as deficits [65]. The eFI score is the number of deficits present, expressed as an equally weighted proportion of the total. An individual with a single deficit would be assigned an eFI of 1/36 (0.03); another with nine deficits would be assigned an eFI of 9/36 (0.25). The eFI score is used to categorise individuals as fit (eFI value of $0-0.12$ ), mild ( $>0.12-0.24)$, moderate $(>0.24-0.36)$, or severely frail (>0.36) [65]. We calculated the eFI retrospectively in the SAIL databank on the cohort index dates using 10 years of previous GP data for each individual each year [66]. This meant that for someone in the cohort for the 1st January 2010, the eFI was calculated using data from 1st January 2000 to 1 st January 2010 . The WIMD quintiles were included as categorical variables ranging from $1-$ Most Deprived, to 5-Least Deprived.

\section{Statistical Methods}

We produced descriptive statistics for our cohorts and stratified these by individuals recorded as having dysphagia and those not. We computed chi-squared statistics with a significance level of 0.05 for each cohort year to investigate differences in age, frailty, gender and WIMD between individuals with and without a dysphagia diagnosis. We calculated multilevel logistic regression models to investigate associations between dysphagia recorded in the previous year and the demographic information. The multilevel logistic regression models included the cohort year as a random effect. Sensitivity analyses included independent multilevel logistic regression models for dysphagia diagnoses in primary care (general practice) and secondary care (hospital) records. Statistical analyses were performed using $\mathrm{R}$ version 4.0.0 [67] with R2MLwiN [68].

\section{Results}

\section{Study Size}

We developed our cohorts by limiting to only individuals aged $65+$ on the index dates, this was further limited by restricting the cohort to individuals registered with a general practice submitting data to the SAIL databank. Finally, we restricted the cohorts to individuals with a valid residential address so we were able to determine the WIMD for each individual. The remaining number of people after these restrictions is recorded in the supplementary material, Table S1.

\section{Recording of Dysphagia and Differences in Demographic Information}

The number of people diagnosed with dysphagia varied with each year. We further stratified the diagnoses by Read code and ICD-10 code. The numbers of codes are recorded in the supplementary material, Table S2. The results suggest an increase in the recording of dysphagia over time and an increase in the number of the types of codes used.

The demographic information over time for the cohorts is recorded in Table 1, with stratified breakdowns for people without a dysphagia diagnosis recorded in Table 2 and those with a dysphagia diagnosis recorded in Table 3 . The change in demographic information over time is also displayed in Fig. 1. Tables 2, 3 and Fig. 1 suggest differences in age, frailty (eFI) and WIMD between those with and without a dysphagia diagnosis, but no significant difference in gender. Table S3 includes the $\mathrm{p}$ values for chi-squared tests for differences in proportions for age, frailty (eFI), gender and WIMD. With the exception of gender, all tests showed significant differences in distributions for individuals with a dysphagia diagnosis compared to those without in the majority of the years tested $(2008,2010-2012,2014-2015$, and 2017-2018).

\section{Multilevel Logistic Regression Results}

The regression results are displayed in Table 4. Multivariate analyses indicated increased odds ratios [OR (95\% confidence intervals)] for a dysphagia diagnosis for increased age [reference 65-74: aged 75-84 OR 1.09 (1.07, 1.12), 85 + OR $1.23(1.20,1.27)$ ], frailty [reference fit: mild frailty $2.45(2.38,2.53)$, moderate frailty $4.64(4.49,4.79)$ and severe frailty $7.87(7.55,8.21)]$, and increased ORs for the most deprived areas [reference 5. Least deprived, 1. Most deprived: $1.10(1.06,1.14)]$. In the univariate analysis, males had a decreased odds of dysphagia diagnosis [OR 0.97 (0.95, $0.99)$ ] but increased odds in the multivariate analysis [OR $1.14(1.11,1.16)]$. The null model has a small, but non-zero, variance at the cohort year level, which suggests that there is variance between the cohort years.

\section{Sensitivity Analyses}

The independent multilevel logistic regression results for the dysphagia diagnoses identified in primary and secondary care are displayed in the supplementary material, Tables S4 and S5, respectively. Results were consistent with the combined analysis but showed an increased odds of a recording of a dysphagia diagnosis in secondary care for those in both 
Table 1 Overall cohort characteristics-Individuals with a general practice registration on the cohort index date

\begin{tabular}{|c|c|c|c|c|c|c|c|c|c|c|c|}
\hline Year & 2008 & 2009 & 2010 & 2011 & 2012 & 2013 & 2014 & 2015 & 2016 & 2017 & 2018 \\
\hline \multicolumn{12}{|l|}{ Individuals } \\
\hline Count $(N)$ & 400,921 & 407,983 & 417,824 & 424,317 & 437,693 & 450,160 & 464,122 & 475,882 & 486,620 & 495,186 & 502,791 \\
\hline \multicolumn{12}{|l|}{ Dysphagia identified } \\
\hline All prior records & $3.6 \%$ & $3.8 \%$ & $4.0 \%$ & $4.3 \%$ & $4.5 \%$ & $4.7 \%$ & $4.9 \%$ & $5.1 \%$ & $5.4 \%$ & $5.6 \%$ & $5.8 \%$ \\
\hline Previous year & $0.6 \%$ & $0.6 \%$ & $0.6 \%$ & $0.6 \%$ & $0.6 \%$ & $0.7 \%$ & $0.7 \%$ & $0.7 \%$ & $0.8 \%$ & $0.7 \%$ & $0.8 \%$ \\
\hline General practice-all prior records & $2.6 \%$ & $2.8 \%$ & $2.9 \%$ & $3.1 \%$ & $3.3 \%$ & $3.4 \%$ & $3.5 \%$ & $3.7 \%$ & $3.8 \%$ & $3.9 \%$ & $4.0 \%$ \\
\hline General practice-previous year & $0.4 \%$ & $0.4 \%$ & $0.4 \%$ & $0.4 \%$ & $0.4 \%$ & $0.4 \%$ & $0.4 \%$ & $0.4 \%$ & $0.4 \%$ & $0.4 \%$ & $0.4 \%$ \\
\hline Hospital—all prior records & $1.4 \%$ & $1.5 \%$ & $1.6 \%$ & $1.8 \%$ & $1.9 \%$ & $2.0 \%$ & $2.1 \%$ & $2.2 \%$ & $2.4 \%$ & $2.6 \%$ & $2.8 \%$ \\
\hline Hospital—previous year & $0.3 \%$ & $0.3 \%$ & $0.3 \%$ & $0.3 \%$ & $0.3 \%$ & $0.3 \%$ & $0.3 \%$ & $0.4 \%$ & $0.4 \%$ & $0.4 \%$ & $0.4 \%$ \\
\hline \multicolumn{12}{|l|}{ Age } \\
\hline $65-74$ & $52.8 \%$ & $53.1 \%$ & $53.4 \%$ & $53.5 \%$ & $54.0 \%$ & $54.7 \%$ & $55.0 \%$ & $55.2 \%$ & $55.6 \%$ & $55.7 \%$ & $55.4 \%$ \\
\hline $75-84$ & $34.4 \%$ & $33.9 \%$ & $33.5 \%$ & $33.3 \%$ & $32.8 \%$ & $32.3 \%$ & $32.1 \%$ & $32.0 \%$ & $31.8 \%$ & $31.7 \%$ & $32.1 \%$ \\
\hline $85+$ & $12.9 \%$ & $13.0 \%$ & $13.1 \%$ & $13.2 \%$ & $13.2 \%$ & $13.0 \%$ & $12.9 \%$ & $12.8 \%$ & $12.6 \%$ & $12.5 \%$ & $12.5 \%$ \\
\hline \multicolumn{12}{|l|}{ Frailty $(e F I)$} \\
\hline Fit & $50.2 \%$ & $48.3 \%$ & $46.6 \%$ & $45.4 \%$ & $44.8 \%$ & $44.9 \%$ & $45.3 \%$ & $46.2 \%$ & $47.0 \%$ & $48.0 \%$ & $48.9 \%$ \\
\hline Mild & $36.2 \%$ & $36.6 \%$ & $36.9 \%$ & $37.3 \%$ & $37.3 \%$ & $37.2 \%$ & $37.0 \%$ & $36.8 \%$ & $36.7 \%$ & $36.4 \%$ & $36.1 \%$ \\
\hline Moderate & $11.4 \%$ & $12.4 \%$ & $13.3 \%$ & $13.9 \%$ & $14.2 \%$ & $14.2 \%$ & $14.0 \%$ & $13.5 \%$ & $13.1 \%$ & $12.6 \%$ & $12.2 \%$ \\
\hline Severe & $2.3 \%$ & $2.7 \%$ & $3.1 \%$ & $3.4 \%$ & $3.7 \%$ & $3.8 \%$ & $3.7 \%$ & $3.5 \%$ & $3.2 \%$ & $3.0 \%$ & $2.8 \%$ \\
\hline \multicolumn{12}{|l|}{ Gender } \\
\hline Female & $55.8 \%$ & $55.5 \%$ & $55.3 \%$ & $55.1 \%$ & $54.9 \%$ & $54.7 \%$ & $54.5 \%$ & $54.3 \%$ & $54.1 \%$ & $54.0 \%$ & $53.8 \%$ \\
\hline Male & $44.2 \%$ & $44.5 \%$ & $44.7 \%$ & $44.9 \%$ & $45.1 \%$ & $45.3 \%$ & $45.5 \%$ & $45.7 \%$ & $45.9 \%$ & $46.0 \%$ & $46.2 \%$ \\
\hline \multicolumn{12}{|l|}{ WIMD 2014} \\
\hline 1. Most deprived & $17.3 \%$ & $17.1 \%$ & $16.9 \%$ & $16.8 \%$ & $16.7 \%$ & $16.6 \%$ & $16.4 \%$ & $16.3 \%$ & $16.5 \%$ & $16.3 \%$ & $16.2 \%$ \\
\hline 2 & $20.5 \%$ & $20.3 \%$ & $20.3 \%$ & $20.1 \%$ & $20.1 \%$ & $19.8 \%$ & $19.7 \%$ & $19.6 \%$ & $19.5 \%$ & $19.5 \%$ & $19.5 \%$ \\
\hline 3 & $20.8 \%$ & $20.8 \%$ & $20.9 \%$ & $20.9 \%$ & $20.9 \%$ & $20.9 \%$ & $21.0 \%$ & $21.2 \%$ & $21.2 \%$ & $21.2 \%$ & $21.2 \%$ \\
\hline 4 & $19.4 \%$ & $19.6 \%$ & $19.6 \%$ & $19.6 \%$ & $19.7 \%$ & $19.8 \%$ & $19.9 \%$ & $19.9 \%$ & $19.8 \%$ & $19.8 \%$ & $19.8 \%$ \\
\hline 5. Least deprived & $22.0 \%$ & $22.2 \%$ & $22.4 \%$ & $22.6 \%$ & $22.6 \%$ & $22.9 \%$ & $22.9 \%$ & $23.0 \%$ & $23.1 \%$ & $23.2 \%$ & $23.3 \%$ \\
\hline
\end{tabular}

the most and second most deprived areas compared to the least deprived with ORs of $1.22(1.17,1.28)$ and $1.08(1.03$, 1.13), respectively.

\section{Discussion}

This is the largest longitudinal study we are aware of to report on the recording of dysphagia using primary and secondary care records in a large cohort of older adults $(65+$ years $)$. The research literature reports that older adults living in the community have a prevalence of dysphagia up to $72 \%$ [15, 17, 28, 69]. This study, in comparison, reports a markedly lower prevalence rate, with dysphagia reported at any time prior to the cohort survey date increasing from 3.6 to $5.8 \%$ between 2008 and 2018 . The percentage of individuals with a diagnosis of dysphagia recorded one year prior to the cohort survey date was consistent over the decade, ranging from 0.6 to $0.8 \%$ in all those aged $65+$ years. The large difference in the percentage of people with identified with dysphagia between our cohort and that reported in other studies raises questions as to what the true prevalence is. Interestingly, our results have shown a higher recording of dysphagia diagnosis in primary care EHR rather than hospital care records. This runs contrary to previous data [14, 45] but may be due to hospital data not relating solely to acute admissions, or the GP taking a more holistic approach, particularly with multiple comorbidities, including frailty who may be at greatest risk of developing dysphagia.

The results of our study confirm associations between age, frailty and identified dysphagia. Dysphagia is a complication of many other medical problems [28, 49], and the literature using hospital-based studies has noted an association between multimorbidity and dysphagia [14, 45, 70]. Our study extends this and reports the increased likelihood of identified dysphagia being present with differing levels of frailty severity identified using primary care records. Compared to individuals characterised as fit, we found increased ORs of 2.45 (2.38, 2.53), $4.63(4.49,4.79)$ and 7.87 (7.55, 8.21 ) for mild, moderate and severe frailty, respectively. As expected, we also found the likelihood of a dysphagia diagnosis increases with age. Compared to those aged 
Table 2 No dysphagia identified in either hospital or general practice records in 1 year prior to cohort index date

\begin{tabular}{|c|c|c|c|c|c|c|c|c|c|c|c|}
\hline Year & 2008 & 2009 & 2010 & 2011 & 2012 & 2013 & 2014 & 2015 & 2016 & 2017 & 2018 \\
\hline \multicolumn{12}{|l|}{ Individuals } \\
\hline$N$ & 398,409 & 405,496 & 415,266 & 421,588 & 434,882 & 447,104 & 460,896 & 472,593 & 482,893 & 491,508 & 498,970 \\
\hline \multicolumn{12}{|l|}{ Age } \\
\hline $65-74$ & $52.8 \%$ & $53.2 \%$ & $53.5 \%$ & $53.6 \%$ & $54.1 \%$ & $54.8 \%$ & $55.2 \%$ & $55.3 \%$ & $55.7 \%$ & $55.8 \%$ & $55.5 \%$ \\
\hline $75-84$ & $34.3 \%$ & $33.9 \%$ & $33.5 \%$ & $33.3 \%$ & $32.8 \%$ & $32.3 \%$ & $32.1 \%$ & $32.0 \%$ & $31.8 \%$ & $31.7 \%$ & $32.1 \%$ \\
\hline $85+$ & $12.8 \%$ & $12.9 \%$ & $13.0 \%$ & $13.1 \%$ & $13.2 \%$ & $12.9 \%$ & $12.8 \%$ & $12.7 \%$ & $12.6 \%$ & $12.5 \%$ & $12.4 \%$ \\
\hline \multicolumn{12}{|l|}{ Frailty $(e F I)$} \\
\hline Fit & $50.3 \%$ & $48.4 \%$ & $46.8 \%$ & $45.6 \%$ & $45.0 \%$ & $45.0 \%$ & $45.5 \%$ & $46.4 \%$ & $47.2 \%$ & $48.2 \%$ & $49.1 \%$ \\
\hline Mild & $36.1 \%$ & $36.6 \%$ & $36.9 \%$ & $37.3 \%$ & $37.3 \%$ & $37.2 \%$ & $37.0 \%$ & $36.8 \%$ & $36.6 \%$ & $36.4 \%$ & $36.1 \%$ \\
\hline Moderate & $11.3 \%$ & $12.3 \%$ & $13.3 \%$ & $13.8 \%$ & $14.1 \%$ & $14.1 \%$ & $13.9 \%$ & $13.4 \%$ & $13.0 \%$ & $12.5 \%$ & $12.0 \%$ \\
\hline Severe & $2.2 \%$ & $2.6 \%$ & $3.1 \%$ & $3.4 \%$ & $3.6 \%$ & $3.7 \%$ & $3.6 \%$ & $3.4 \%$ & $3.2 \%$ & $2.9 \%$ & $2.8 \%$ \\
\hline \multicolumn{12}{|l|}{ Gender } \\
\hline Female & $55.8 \%$ & $55.5 \%$ & $55.3 \%$ & $55.1 \%$ & $54.9 \%$ & $54.6 \%$ & $54.5 \%$ & $54.3 \%$ & $54.1 \%$ & $54.0 \%$ & $53.9 \%$ \\
\hline Male & $44.2 \%$ & $44.5 \%$ & $44.7 \%$ & $44.9 \%$ & $45.1 \%$ & $45.4 \%$ & $45.5 \%$ & $45.7 \%$ & $45.9 \%$ & $46.0 \%$ & $46.1 \%$ \\
\hline \multicolumn{12}{|l|}{ WIMD 2014} \\
\hline 1. Most deprived & $17.3 \%$ & $17.1 \%$ & $16.8 \%$ & $16.8 \%$ & $16.7 \%$ & $16.5 \%$ & $16.4 \%$ & $16.3 \%$ & $16.4 \%$ & $16.3 \%$ & $16.2 \%$ \\
\hline 2 & $20.5 \%$ & $20.3 \%$ & $20.3 \%$ & $20.1 \%$ & $20.1 \%$ & $19.8 \%$ & $19.7 \%$ & $19.6 \%$ & $19.5 \%$ & $19.5 \%$ & $19.5 \%$ \\
\hline 3 & $20.8 \%$ & $20.8 \%$ & $20.9 \%$ & $20.9 \%$ & $20.9 \%$ & $20.9 \%$ & $21.0 \%$ & $21.2 \%$ & $21.2 \%$ & $21.2 \%$ & $21.2 \%$ \\
\hline 4 & $19.5 \%$ & $19.6 \%$ & $19.6 \%$ & $19.6 \%$ & $19.7 \%$ & $19.8 \%$ & $19.9 \%$ & $19.9 \%$ & $19.8 \%$ & $19.8 \%$ & $19.8 \%$ \\
\hline 5. Least deprived & $22.0 \%$ & $22.2 \%$ & $22.4 \%$ & $22.6 \%$ & $22.7 \%$ & $22.9 \%$ & $23.0 \%$ & $23.1 \%$ & $23.1 \%$ & $23.2 \%$ & $23.3 \%$ \\
\hline
\end{tabular}

Table 3 Dysphagia identified in either hospital or general practice records 1 year prior to cohort index date

\begin{tabular}{lccccccccccc}
\hline Year & 2008 & 2009 & 2010 & 2011 & 2012 & 2013 & 2014 & 2015 & 2016 & 2017 & 2018 \\
\hline Individuals & & & & & & & & & & \\
$N$ & 2,512 & 2,487 & 2,558 & 2,729 & 2,811 & 3,056 & 3,226 & 3,289 & 3,727 & 3,678 & 3,821 \\
Age & & & & & & & & & & & \\
$65-74$ & $41.4 \%$ & $40.5 \%$ & $37.6 \%$ & $39.7 \%$ & $40.4 \%$ & $41.2 \%$ & $39.6 \%$ & $40.6 \%$ & $43.1 \%$ & $42.3 \%$ & $42.3 \%$ \\
$75-84$ & $38.7 \%$ & $38.4 \%$ & $39.7 \%$ & $37.7 \%$ & $36.9 \%$ & $36.7 \%$ & $37.8 \%$ & $37.8 \%$ & $36.7 \%$ & $37.0 \%$ & $37.2 \%$ \\
$85+$ & $19.9 \%$ & $21.0 \%$ & $22.7 \%$ & $22.6 \%$ & $22.7 \%$ & $22.1 \%$ & $22.6 \%$ & $21.6 \%$ & $20.3 \%$ & $20.8 \%$ & $20.4 \%$ \\
Frailty (eFI) & & & & & & & & & & & \\
Fit & $24.0 \%$ & $21.5 \%$ & $21.0 \%$ & $20.1 \%$ & $19.6 \%$ & $19.3 \%$ & $19.9 \%$ & $18.5 \%$ & $20.6 \%$ & $21.0 \%$ & $20.5 \%$ \\
Mild & $40.4 \%$ & $41.2 \%$ & $40.9 \%$ & $39.0 \%$ & $39.8 \%$ & $38.0 \%$ & $38.3 \%$ & $41.2 \%$ & $41.1 \%$ & $40.1 \%$ & $41.5 \%$ \\
Moderate & $27.6 \%$ & $27.5 \%$ & $26.6 \%$ & $28.4 \%$ & $28.0 \%$ & $28.5 \%$ & $29.4 \%$ & $27.6 \%$ & $26.8 \%$ & $27.6 \%$ & $27.5 \%$ \\
Severe & $8.0 \%$ & $9.8 \%$ & $11.4 \%$ & $12.5 \%$ & $12.5 \%$ & $14.2 \%$ & $12.4 \%$ & $12.7 \%$ & $11.5 \%$ & $11.3 \%$ & $10.4 \%$ \\
Gender & & & & & & & & & & & \\
Female & $56.7 \%$ & $58.5 \%$ & $55.8 \%$ & $56.5 \%$ & $56.2 \%$ & $56.4 \%$ & $55.4 \%$ & $52.6 \%$ & $55.9 \%$ & $54.4 \%$ & $52.6 \%$ \\
Male & $43.3 \%$ & $41.5 \%$ & $44.2 \%$ & $43.5 \%$ & $43.8 \%$ & $43.6 \%$ & $44.6 \%$ & $47.4 \%$ & $44.1 \%$ & $45.6 \%$ & $47.4 \%$ \\
WIMD 2014 & & & & & & & & & & & \\
1. Most deprived & $20.5 \%$ & $19.1 \%$ & $20.4 \%$ & $18.8 \%$ & $19.4 \%$ & $19.9 \%$ & $19.5 \%$ & $19.4 \%$ & $19.0 \%$ & $19.3 \%$ & $19.1 \%$ \\
2 & $19.7 \%$ & $22.0 \%$ & $21.1 \%$ & $20.7 \%$ & $21.4 \%$ & $20.4 \%$ & $20.3 \%$ & $20.4 \%$ & $20.1 \%$ & $19.8 \%$ & $20.9 \%$ \\
3 & $19.8 \%$ & $20.6 \%$ & $20.9 \%$ & $21.4 \%$ & $20.5 \%$ & $20.2 \%$ & $19.3 \%$ & $21.5 \%$ & $20.0 \%$ & $21.3 \%$ & $20.0 \%$ \\
4 & $18.6 \%$ & $18.0 \%$ & $18.2 \%$ & $18.8 \%$ & $17.3 \%$ & $18.8 \%$ & $19.4 \%$ & $17.9 \%$ & $18.5 \%$ & $18.5 \%$ & $18.1 \%$ \\
5. Least deprived & $21.3 \%$ & $20.3 \%$ & $19.5 \%$ & $20.3 \%$ & $21.5 \%$ & $20.7 \%$ & $21.5 \%$ & $20.8 \%$ & $22.4 \%$ & $21.1 \%$ & $21.9 \%$ \\
\hline & & & & & & & & & & &
\end{tabular}

65-74, we noted increased ORs of $1.10(1.07,1.12)$ and 1.23 $(1.20,1.27)$ for those aged $75-84$ and $85+$, respectively. Although these findings are not novel, we have used a large dataset to provide robust evidence that frail older adults are particularly vulnerable and at a high risk of having, or potentially developing, dysphagia.

Our study has suggested an association between identified dysphagia and deprivation, with people living in the 

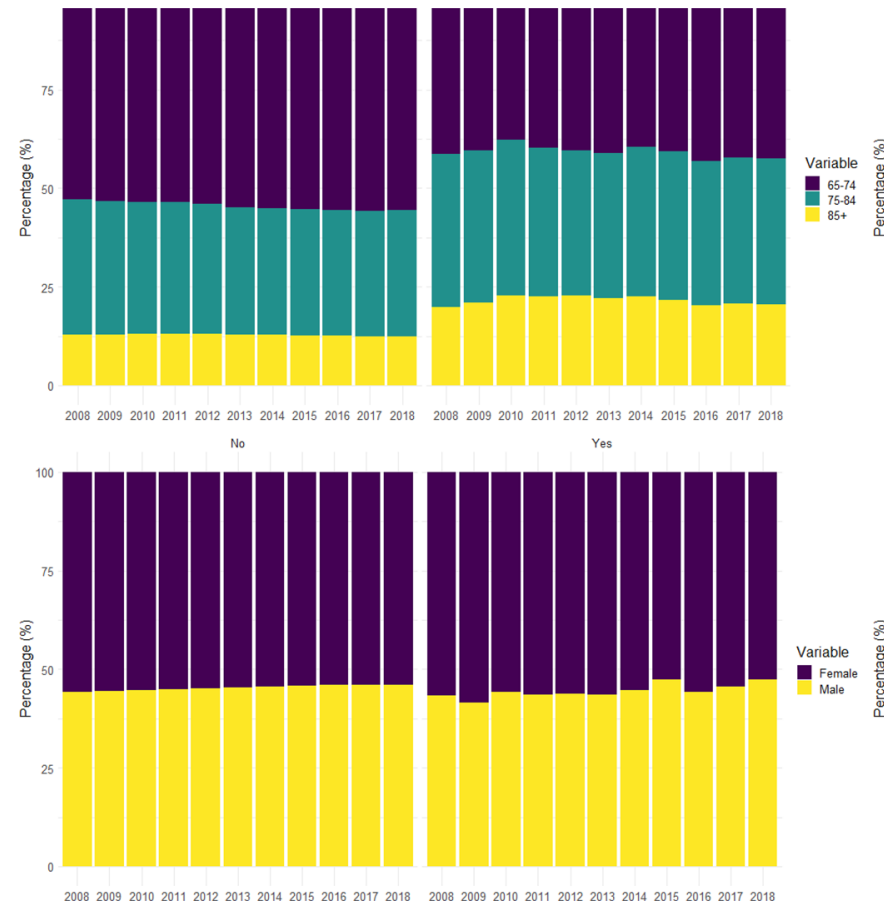

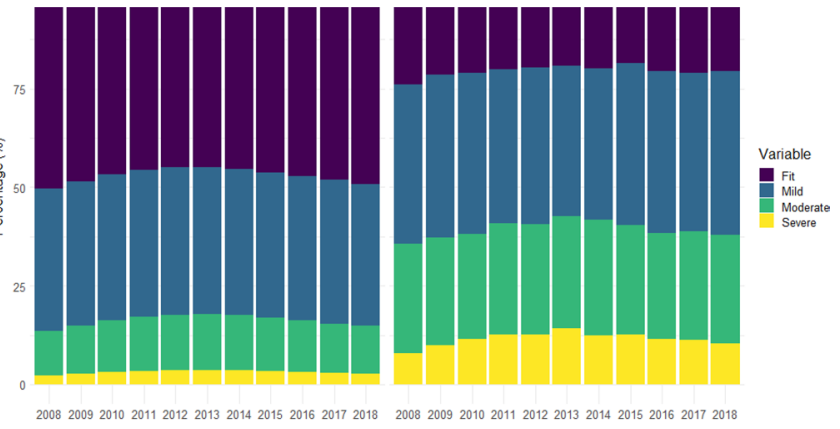

№

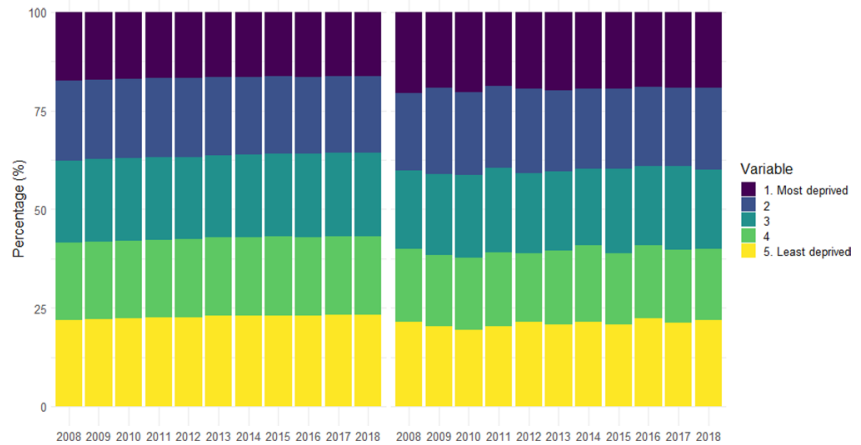

Fig. 1 Demographic differences between individuals identified with dysphagia in hospital or general practice records in the year before cohort entry: 2008 and 2018

most deprived areas compared to the least deprived areas having an increased OR of $1.10(1.06,1.14)$. There are no documented studies we are aware of demonstrating this association. Deprivation is defined as a lack of access to basic needs such as food, shelter, clothing, health and education. Lower socio-economic class is associated with an increase in smoking, risky drinking habits, lack of exercise, poor diet [71] and often reduced self-care and increased risk of hospitalisations [72, 73], all synonymous with deprivation. A consequence of deprivation is the risk of malnutrition, illness, mortality, frailty and an increase in complex multimorbidity [74]. The increase in social deprivation, age and frailty (including oral frailty) manifests itself in the most vulnerable [14] in the form of an old age quartet (dysphagia, frailty, malnutrition and sarcopenia); with this subset of the population likely to have a particularly high prevalence of dysphagia. This is supported by our finding that the documentation of dysphagia in secondary care is more common [OR $1.100(1.063,1.138)]$ in people from deprived areas.

Our study has analysed data recorded as part of health and social care interaction, as opposed to using a survey. Studies show that many people do not report their swallowing difficulties to a health care professional. For example, Chen et al. found that $24 \%$ of those with swallowing problems did not report them to their family or doctor [75]. Wilkins et al. found that $2 \%$ of 947 people $\geq 18$ years of age reported dysphagia at least several times a month, but $46 \%$ had not reported the problem to their GP [24].
Similarly, Adkins et al. reported that 2445 of 4998 (49\%) survey participants had not consulted a health care practitioner [20]. In the USA, Bhattacharyya et al. estimated that 9.4 million adults had had dysphagia in the previous year [33]. This was extrapolated from a cohort of 1554 (4\%) of the sample reporting dysphagia, where $22.7 \%$ (353) had seen a health care professional, 36.9\% (130) had received a confirmed diagnosis and $56.5 \%$ reported that their swallow was a moderate/big/very big problem. It is possible that the failure to report swallowing problems, compounded with the failure to enquire about/screen for swallowing problems, accounts for some of the discrepancy in the prevalence between our study and previously reported data.

As all studies have asked a slightly different question regarding swallowing, swallowing problems or dysphagia, and some are more detailed than others, each study provides an independent, rather than complementary, part of the jigsaw. When considering studies that have used surveys and questionnaires, it should be noted that survey responses are influenced by the ability to understand the question, the ability to recall relevant information [76], the willingness of the participant to show normative behaviour and the willingness to please [77]. Face-to-face interviews are reliant on the interaction between the interviewer and the participant, including the behaviour of the interviewer [78], and in both telephone/postal and face-to-face interviews, the length of the survey may provoke a more negative response [79]. 
Table 4 Univariate and multivariate multilevel logistic regression model with fixed effects for age, frailty (electronic frailty index), gender and welsh index of multiple deprivation

\begin{tabular}{|c|c|c|c|c|c|c|}
\hline $\begin{array}{l}\text { Odds ratios ( } 95 \% \\
\text { confidence interval) }\end{array}$ & Null & Age & Frailty & Gender & WIMD & Multivariate \\
\hline \multicolumn{7}{|l|}{$\begin{array}{l}\text { Age (reference: } \\
65-74)\end{array}$} \\
\hline $75-84$ & - & $\begin{array}{l}1.541(1.504, \\
1.579)\end{array}$ & - & - & - & $\begin{array}{c}1.093(1.066, \\
1.120)\end{array}$ \\
\hline $85+$ & - & $\begin{array}{l}2.240(2.177, \\
2.305)\end{array}$ & - & - & - & $\begin{array}{l}1.234(1.196, \\
1.272)\end{array}$ \\
\hline \multicolumn{7}{|c|}{ Frailty (electronic frailty index, reference: fit) } \\
\hline Mild & - & - & $\begin{array}{l}2.515(2.443, \\
2.589)\end{array}$ & - & - & $\begin{array}{l}2.453(2.382, \\
2.527)\end{array}$ \\
\hline Moderate & - & - & $\begin{array}{l}4.897(4.747, \\
5.053)\end{array}$ & - & - & $\begin{array}{l}4.637 \text { (4.487, } \\
4.793)\end{array}$ \\
\hline Severe & - & - & $\begin{array}{l}8.478(8.149, \\
8.821)\end{array}$ & - & - & $\begin{array}{l}7.872(7.548, \\
8.210)\end{array}$ \\
\hline \multicolumn{7}{|l|}{$\begin{array}{l}\text { Gender (reference: } \\
\text { female) }\end{array}$} \\
\hline Male & - & - & - & $\begin{array}{l}0.971(0.951, \\
0.992)\end{array}$ & - & $\begin{array}{c}1.135(1.111, \\
1.160)\end{array}$ \\
\hline \multicolumn{7}{|c|}{ Welsh index of multiple deprivation 2014 (Reference: 5 . least deprived) } \\
\hline 1. Most deprived & - & - & - & - & $1.269(1.227,1.312)$ & $\begin{array}{c}1.100(1.063, \\
1.138)\end{array}$ \\
\hline 2 & - & - & - & - & $\begin{array}{l}1.121(1.085, \\
1.159)\end{array}$ & $\begin{array}{l}1.010(0.977, \\
1.044)\end{array}$ \\
\hline 3 & - & - & - & - & $\begin{array}{l}1.053(1.019, \\
1.089)\end{array}$ & $\begin{array}{l}0.973(0.941, \\
1.006)\end{array}$ \\
\hline 4 & - & - & - & - & $\begin{array}{l}1.005(0.972, \\
1.040)\end{array}$ & $\begin{array}{l}0.955(0.923, \\
0.989)\end{array}$ \\
\hline Intercept & $\begin{array}{l}0.007(0.007 \\
0.007)\end{array}$ & $\begin{array}{l}0.005(0.005 \\
0.005)\end{array}$ & $\begin{array}{l}0.003(0.003 \\
0.003)\end{array}$ & $\begin{array}{l}0.007(0.007, \\
0.007)\end{array}$ & $\begin{array}{l}0.006(0.006 \\
0.007)\end{array}$ & $\begin{array}{l}0.003(0.003, \\
0.003)\end{array}$ \\
\hline \multicolumn{7}{|l|}{ Random effects } \\
\hline $\begin{array}{l}\text { Level } 2 \text { variance } \\
\text { (annum) }\end{array}$ & $\begin{array}{l}0.006(0.001, \\
0.012)\end{array}$ & $\begin{array}{l}0.007(0.001, \\
0.013)\end{array}$ & $\begin{array}{l}0.008(0.001, \\
0.014)\end{array}$ & $\begin{array}{l}0.006(0.001, \\
0.012)\end{array}$ & $\begin{array}{l}0.006(0.001 \\
0.012)\end{array}$ & $\begin{array}{l}0.007(0.001, \\
0.014)\end{array}$ \\
\hline- & - & - & - & - & - & - \\
\hline Observations & $4,963,499$ & $4,963,499$ & $4,963,499$ & $4,963,499$ & $4,963,499$ & $4,963,499$ \\
\hline $\begin{array}{l}\text { Level } 2 \text { groups } \\
\text { (years) }\end{array}$ & 11 & 11 & 11 & 11 & 11 & 11 \\
\hline
\end{tabular}

The cohort year was included as a random effect

In summary, there are two possible interpretations for the differences in reported prevalence of dysphagia diagnoses in the literature and diagnosed dysphagia in our study: first, there are people in the community with swallowing difficulties who have not been identified and are not receiving support from either their GP, speech and language therapist, or dietitian; or second, the community prevalence of dysphagia is not as great as previously reported.

\section{Limitations}

We included only individuals with a confirmed general practice registration on the cohort index date. We were unable to include $100 \%$ coverage of the Welsh population due to some general practices not contributing data to the SAIL databank. As with many data linkage studies, we did not have perfect matching between primary care and administrative records which meant some individuals were lost when including demographic information. In addition, we acknowledge the limitations of a diagnosis of dysphagia being recorded in electronic health records as it may not be a primary diagnosis, there may be errors in coding and in common with many studies, there is no clear definition of dysphagia.

The information collected and documented in medical records is limited by the need for specific codes which may not be sensitive enough to accurately represent medical 
problems. Health care professionals do not routinely ask or screen for swallowing [55] even if there are well-documented neurological disease such as stroke, dementia or Parkinson's disease.

There is no accepted, unifying definition of dysphagia, and this study has used a series of read codes and ICD10 codes to capture swallowing problems/dysphagia. Some of these codes may not directly relate to oropharyngeal dysphagia.

\section{Strengths}

We performed a large longitudinal data linkage study of over 400,000 individuals per year. This adds significant and novel evidence for the levels of recording of dysphagia in older adults. We were able to link primary and secondary care data together with administrative data to gain insights to the associations between dysphagia and the included demographics.

\section{Conclusion}

The study has identified a lower prevalence of diagnosed dysphagia than previously reported. The results have confirmed the association of identified dysphagia with increasing age and frailty. A previously unreported association with deprivation has been identified. The aetiology of deprivation is a multifactorial, affecting physical and mental health, often resulting in poor nutrition, long-term ill health and a short-end life span. That is known to affect health outcomes and the association with dysphagia should not be a surprise. Further research exploring the inter-relationship between dysphagia and health and social factors contributing to deprivation is indicated.

Supplementary Information The online version contains supplementary material available at https://doi.org/10.1007/s00455-022-10425-5.

Funding This work was supported by the Medical Research Council [MR/V028367/1]; Health and Care Research Wales [Project: SCF-181504]; Health Data Research UK [HDR-9006] which receives its funding from the UK Medical Research Council, Engineering and Physical Sciences Research Council, Economic and Social Research Council, Department of Health and Social Care (England), Chief Scientist Office of the Scottish Government Health and Social Care Directorates, Health and Social Care Research and Development Division (Welsh Government), Public Health Agency (Northern Ireland), British Heart Foundation (BHF) and the Wellcome Trust; and Administrative Data Research UK which is funded by the Economic and Social Research Council [Grant ES/S007393/1]. Funding for this particular aspect of the work was via the Sidney De Hann Trust.

\section{Declarations}

Conflict of interest We have no conflict of interest to declare.
Open Access This article is licensed under a Creative Commons Attribution 4.0 International License, which permits use, sharing, adaptation, distribution and reproduction in any medium or format, as long as you give appropriate credit to the original author(s) and the source, provide a link to the Creative Commons licence, and indicate if changes were made. The images or other third party material in this article are included in the article's Creative Commons licence, unless indicated otherwise in a credit line to the material. If material is not included in the article's Creative Commons licence and your intended use is not permitted by statutory regulation or exceeds the permitted use, you will need to obtain permission directly from the copyright holder. To view a copy of this licence, visit http://creativecommons.org/licenses/by/4.0/.

\section{References}

1. World Bank Statistics. https://data.worldbank.org/indicator/SP. POP.65UP.TO.ZS?view=chart. Accessed 9 Dec 2019

2. Eurostats. European Health Information Gateway European Mortality Database. 2019. https://gateway.euro.who.int/en/datasets/ european-mortality-database/\#population-and-icd-used. Accessed 9 Dec 2019

3. World Health Organization European Health Information Gateway. European Mortality Database. World Health Organization

4. Regional Office for Europe. Copenhagen. 2020. https://gatew ay.euro.who.int/en/datasets/european-mortalitydatabase/\#popul ation-and-icd-used. Accessed 19 June 2020

5. Chen X, Mao G, Leng SX. Frailty syndrome: an overview. Clin Interv Aging. 2014;9:433-41.

6. Overview of the UK Population: August 2019. https://www.ons. gov.uk/peoplepopulationandcommunity/populationandmigration/ populationestimates/articles/overviewoftheukpopulation/augus t2019. Accessed 19 June 2020

7. Dodds WJ, Stewart ET, Logemann JA. Physiology and radiology of the normal oral and pharyngeal phases of swallowing. Am J Roentgenol. 1990;154(5):953-63.

8. Martin BJW, et al. Coordination between respiration and swallowing: respiratory phase relationships and temporal integration. J Appl Physiol. 1994;76(2):714-23.

9. Roden DF, Altman KW. Causes of dysphagia among different age groups: a systematic review of the literature. Otolaryngol Clin N Am. 2013;46(6):965-87.

10. Daniels SK, et al. Mechanism of sequential swallowing during straw drinking in healthy young and older adults. J Speech Lang Hear Res. 2004;47(1):33-45.

11. Cavallero S, Dominguez LJ, Vernuccio L, Barbagallo M. Presbyphagia and dysphagia in old age. Geriatric Care. 2020. https://doi. org/10.4081/gc.2020.9137.

12. Boss GR, Seegmiller JE. Age-related physiological changes and their clinical significance. West J Med. 1981;135:434-40.

13. McCullough GH, Wertz RT, Rosenbeck JC, Suiter D, McCoy SC. Defining swallowing function by age promises and pitfalls of pigeonholing. J Speech Lang Hear Res. 2007;48:1280-93. https:// doi.org/10.1044/1092-4388(2005/089.

14. Humbert IA, Robbins J. Dysphagia in the elderly. Phys Med Rehabil Clin N Am. 2008;19:853-66.

15. Madhaven A, Lagorio LA, Crary MA, Dahl WJC, Carnaby GD. Prevalence and risk factors for dysphagia in the community dwelling elderly: a systematic review. J Nutr Aging Health. 2016;20:806-15.

16. Brates D, Troche MS, Molfenter SM. The role of fatigue in the aging swallow: a review. OBM Geriatrics. 2021. https://doi.org/ 10.21926/obm.geriatr.2102166. 
17. Mancopes R, Gandhi P, Smaul S, Steele CM. Which physiological swallowing parameters change with health aging. OBM Geriatrics. 2020. https://doi.org/10.21926/obm.geriatr.2101153.

18. Smithard D, Hansjee D, Henry D, Mitchell L, Sabaharwal A, Salkeld J, Yeung E, Younus O, Swaine I. Inter-relationships between frailty, sarcopenia, undernutrition and dysphagia in older people who are admitted to acute frailty and medical wards: Is there an older adult quartet? Geriatrics. 2020;5:41. https://doi. org/10.3390/geriatrics5030041.

19. Bloem BR, et al. Prevalence of subjective dysphagia in community residents aged over 87. BMJ. 1990;300(6726):721-2.

20. Adkins $C$, et al. Prevalence and characteristics of dysphagia based on a population-based survey. Clin Gastroenterol Hepatol. 2020;18(9):1970-9.

21. Kertscher B, et al. Prevalence of oropharyngeal dysphagia in the Netherlands: a telephone survey. Dysphagia. 2015;30(2):114-20.

22. Nimmons D, et al. A longitudinal study of symptoms of oropharyngeal dysphagia in an elderly community-dwelling population. Dysphagia. 2016;31(4):560-6.

23. Cho SY, et al. Prevalence and risk factors for dysphagia: a USA community study. Neurogastroenterol Motil. 2015;27(2):212-9.

24. Wilkins $\mathrm{T}$, et al. The prevalence of dysphagia in primary care patients: a HamesNet research network study. J Am Board Fam Med. 2007;20(2):144-50.

25. Eslick GD, Talley NJ. Dysphagia: epidemiology, risk factors and impact on quality of life: a population-based study. Aliment Pharmacol Ther. 2008;27(10):971-9.

26. Holland G, Jayaseker V, Pendleton N, Horan M, Jones M, Hamdy $\mathrm{S}$. Prevalence and symptom profiling of oropharyngeal dysphagia in a community dwelling of an elderly population: a self-reporting questionnaire survey. Dis Esophagus. 2011;24:476-80.

27. Leslie $P$, Smithard DG. Is dysphagia under diagnosed or is normal swallowing more variable than we think? Reported swallowing problems in people aged 18-65 years. Dysphagia. 2020. https:// doi.org/10.1007/s00455-020-10213-z.

28. Khader FA, Gangadhara SKS. Swallowing difficulties among healthy elderly: prevalence and aetiology. Int J Otorhinolaryngol Head Neck Surg. 2018;4:494.

29. Watson DI, Lalley CJ. Prevalence of symptoms and use of medication for gastroesophageal reflux in an Australian community. World J Surg. 2009;33:88. https://doi.org/10.1007/ s00268-008-9780-9.

30. Ruth M, Mansson I, Sanberg N. The prevalence of symptoms suggestive of esophageal disorders. Scand J Gastroenterol. 1991;26:73-81. https://doi.org/10.3109/00365529108996486.

31. Cho SY, Choung RS, Saito YA, Schleck CD, Zinsmeister AR, Locke GR III, Talley NJ. Prevalence and risk factors for dysphagia: a US community study. Neurogastroenterol Motil. 2015;27:212-9. https://doi.org/10.1111/nmo.12467.

32. Chiocca JC, Olmos JA, Salis GB, Soifer LO, Higa R, Marcolongo $\mathrm{M}$. The Argentinian gastro-oesophageal reflux study group. Aliment Pharmacol Ther. 2005;22:331-42. https://doi.org/10.1111/j. 1365-2036.2005.02565.x.

33. Bhattacharyya $\mathrm{N}$. The prevalence of dysphagia among adults in the United States. Otolaryngol Head Neck Surg. 2014;151(5):765-9.

34. Andersen O, Zweidorff OK, Hjelde T, Rødland EA. Problems when swallowing tablets. A questionnaire study for general practice. Tidsskrift Norske Laegeforening. 1995;115(8):947-9.

35. Kawashima K, Motohashi Y, Fujishima I. Prevalence of dysphagia among community-dwelling elderly individuals as estimated using a questionnaire for dysphagia screening. Dysphagia. 2004;19:266-71. https://doi.org/10.1007/s00455-004-0013-6.

36. Yang EJ, Kim MH, Lim J-Y, Paik N-J. Oropharyngeal dysphagia in a community-based elderly cohort: the Korean longitudinal study on health and aging. J Korean Med Sci. 2013;28:1534-9. https://doi.org/10.3346/jkms.2013.28.10.1534.
37. Patel DA, Krishnaswami S, Steger E, Conover E, Vaezi MF, Ciucci MR, Francis DO. Economic and survival burden of dysphagia among inpatients in the United States. Dis Esoph. 2018. https://doi.org/10.1093/dote/dox 131.

38. Morely JE. Oral frailty. J Nutr Health Aging. 2020;24:683-4.

39. Hoogendijke EO, Afilalo J, Ensrud KE, Kowal P, Onder G, Fried LP. Frailty: implications for clinical practice and public health. Lancet. 2019;294:1365-75.

40. Fried LP, Tangen CM, Watson J, Newman AB, Hirsch C, Gottdiener J, Seeman T, Tracy R, Kop WJ, Burke G, McBurnie MA. Frailty in older adults: evidence of phenotype. J Gerontol Med Sci. 2001;56A:M146-56.

41. Mitnitski AB, Mogilner AJ, Rockwood K. Accumulation of deficits as a proxy measure of aging. Sci World J. 2001;1:323-36.

42. Morely JE, Vellas B, van Kan GA, Anker SD, Bauer JM, Bernabei R, Cesari M, Chumlea WC, Doehner W, Evans J, Fried LP, Guralnik JM, Katz PR, Malmstrom TK, McCarter RJ, Robledo LMG, Rockwood K, von Haehling S, Vandewoude MF, Walston J. Frailty consensus: a call to action. J Am Med Dir Assoc. 2013;4:392-7. https://doi.org/10.1016/j.jamda.2013.03.022.

43. Dent E, Grande ED, Price K, Taylor AW. Frailty and usage of health care systems: results from the South Australian monitoring and surveillance system (SAMSS). Maturitas. 2017;104:36-43.

44. Clegg A, Young J, Illife S, Rikkert MO, Rockwood K. Frailty in elderly people. Lancet. 2013;381:2-8.

45. Carrion S, Roca M, Costa A, Arreola V, Ortega O, Palomera E, Serra-Pratt M, Cabre M, Clave P. Nutritional status of older people with oropharyngeal dysphagia in a chronic vs acute clinical situation. Clin Nutr. 2017;36:1110-6.

46. Wang CH, Charlton B, Kohlwes J. The horrible taste of nectar and honeyinappropriate use of thickened liquids in dementia: a teachable moment. JAMA Intern Med. 2016;176:735-6.

47. Dibello V, Zupo R, Sardone R, Lozupone M, Castellana F, Dibello A, Daniele A, De Pergola G, Bortone I, Lampignano L, Giannelli G, Panza F. Oral frailty and its determinates in older age: a systematic review. Lancet Health Longev. 2021;2:e507-20.

48. Tanaka T, Takahashi K, Hirano H, Kikutani T, Watanabe Y, Ohara Y, Furuya H, Teysuo T, Akishita M, Iijima K. Oral frailty as a risk factor for physical frailty and mortality in community-dwelling elderly. J Gerontol. 2018;73:1661-7. https://doi.org/10.1093/ gerona/glx225.

49. Cha S, Kim W-S, Kim KW, Jang HK, Lim S, Paik N-J. Sarcopenia is an independent risk factor for dysphagia in community dwelling older adults. Dysphagia. 2019;34:692-7.

50. Hansen T, Nielsen RL, Houlind MB, Tavenier J, Rassmussen LJH, Jørgensen LM, Treldal C, Beck AM, Pedersen MM, Andersen O, Petersen J, Andersen AL. Dysphagia prevalence, time course, and association with probable sarcopenia, inactivity, malnutrition, and disease status in older patients admitted to an emergency department: a secondary analysis of cohort study data. Geriatrics. 2021;6:46. https://doi.org/10.3390/geriatrics6020046.

51. Baijens LWJ, Clave P, Cras P, Ekberg O, Forster A, Kolb GF, Leners JC, Masiero S, Mateos-Nozal J, Ortega O, et al. European society for swallowing disorders-European Union Geriatric Medicine Societywhite paper: oropharyngeal dysphagia as a geriatric syndrome. CIA. 2016;11:1403-28.

52. Smithard DG. Swallowing and eating difficulties in institutionalised patients. Clin Rehabil. 1996;2:153-4.

53. Takizawa C, Gemmell E, Kenworthy J, Speyer R. A systematic review of the prevalence of oropharyngeal dysphagia in stroke, Parkinson's disease, Alzheimer's disease, head injury and pneumonia. Dysphagia. 2016;31:434-41.

54. Malagelada J-R, Bazzoli F, Boeckxstaens G, De Looze D, Fried M, Kahrilas P, Lindberg G, Malfertheiner P, Salis G, Sharma P, Sifrim D, Vakil N, Le Mair A. World gastroenterology 
organisation global guidelines: dysphagia — global guidelines and cascades September 2014. J Clin Gastroenterol. 2015;49(5):370 8. https://doi.org/10.1097/MCG.0000000000000307.

55. Smithard D, Westmark S, Melgaard D. Evaluation of the prevalence of screening for dysphagia among older people admitted to medical services - an international survey. Geriatrics. 2019;3:1-8.

56. Gallegos C, Brito-de la Fueente E, Clave P, Costa A, Assegehegen G. Nutritional aspects of dysphagia management. Adv Food Nutr Res. 2017;81:271-318.

57. Wirth R, Pourhassan M, Streicher M, Hiesmayr M, Schindler K, Sieber C, Volkert D. The impact of dysphagia on mortality of nursing home residents: results from the nutrition day project. JAMDA. 2018;19:775-8.

58. Casey JA, Schwartz BS, Stewart WF, Adler NE. Using electronic health records for population health research: a review of methods and applications. Ann Rev Public Health. 2016;37:61-81.

59. Todd OM, Burton JK, Dodds RM, Hollinghurst J, Lyons RA, Quinn TJ, Schneider A, Walesby KE, Wilkinson C, Conroy S, Gale C, Hall M, Walters K, Clegg AP. New Horizons in the use of routine data for ageing research. Age Ageing. 2020;49:716-22.

60. Lyons RA, Jone KH, John G, Brooks CJ, Verplancke JP, Ford DV, Brown G, Leake K. The SAIL databank: linking multiple health and social care datasets. BMC Med Inform Decis Making. 2009;9:3. https://doi.org/10.1186/1472-6947-9-3.

61. Ford DV, Jone KH, Verplancke JP, Lyons RA, John G, Brown G, Brooks CJ, Thompson S, Bodger O, Couch T, Leak K. The SAIL Databank: building a national architecture for e-health research and evaluation. BMC Health Serv Res. 2009;9:157. https://doi. org/10.1186/1472-6963-9-157.

62. Jones KH, Ford DV, Jones C, Dsilva R, Thompson S, Brooks CJ, Heaven ML, Thayer DS, McNerney CL, Lyons RA. A case study of the secire anonymous information linkage (SAIL) gateway: a privacy-protecting remote access system for health-related research and evaluation. J Biomed Inform. 2014;50:196-204.

63. Rodgers SE, Lyons RA, Dsilva R, Jones KH, Brooks CJ, Ford DV, John G, Verplancke JP. Residential anonymous linking fields (RALFs): a novel information infrastructure to study the interaction between the environment and individuals health. J Pub Health. 2009;31:582-8. https://doi.org/10.1093/pubmed/fdp041.

64. StatsWales, "Welsh Index of Multiple Deprivation 2019," 2019. https://statswales.gov.wales/Catalogue/Community-Safety-andSocial-Inclusion/Welsh-Index-of-Multiple-Deprivation/WIMD2019. Accessed 11 Dec 2020

65. Clegg A, Bates C, Young J, Ryan R, Nichols L, Teale EA, Mohammed MA, Parry J, Marshall T. Development and validation of an electronic frailty index using routine primary care electronic health record data. Age Ageing. 2016;45:353-60.

66. Hollinghurst J, Fry R, Akbari A, Clegg A. External validation of the electronic frailty index using the population of wales within the secure anonymised information linkage databank. Age Ageing. 2019;48:922-6. https://doi.org/10.1093/ageing/afz110.

67. R Core Team. R: a language and environment for statistical computing. Vienna: R Core Team; 2020.
68. Zhang Z, Parker RMA, Charlton CMJ, Leckie G, Browne WJ. R2MLwiN\}: a package to run $\{$ MLwiN from within $\{R\}$. J Stat Softw. 2016;72:1-43.

69. Clave P, Shaker R. Dysphagia: current reality and scope of the problem. Nat Rev Gastroenterol Hepatol. 2015;12:259-70.

70. Cabre M, Serra-Pratt M, Palomera E, Almirall J, Pallares R, Clavé P. Prevalence and prognostic implications of dysphagia in elderly patients with pneumonia. Age Ageing. 2010;39:39-45. https://doi. org/10.1093/ageing/afp100.

71. Drieskens S, van Oyen H, Demarest S, Van der Haeyden J, Gisle L, Tafforeau J. Multiple risk behaviour: increasing socio-economic gap over time. Eur J Pub Health. 2010;20:634-9. https:// doi.org/10.1093/eurpub/ckp185.

72. Ribero UASL, Vicente LCC, Lemos SMA. Functional literacy in adults an delderly with dysphagia. Audil Commun Res. 2021. https://doi.org/10.1590/2317-6431-2020-235.

73. Chan MS, van den Hout A, Pujades-Rodriguez M, Jones MM, Matthews FE, Jagger C, Raine R, Bajekal M. Socio-economic inequalities in life expectancy of older adults with and without multimorbidity: a record linkage study of 1.1 million people in England. Int J Epidemiol. 2019;48:1340-51. https://doi.org/10. 1093/ije/dyz052.

74. Head A, Fleming K, Kypridemos C, Pearson-Stuttard J, O'Flaherty M. Multimorbidity: the case for prevention. J Epidemiol Community Health. 2021;75:42-4. https://doi.org/10.1136/ jech-2020-214301.

75. Chen PH, Golub JS, Hapner ER, Johns IIIM. Prevalence of perceived dysphagia and quality of life impairment in a geriatric population. Dysphagia. 2009;24:1-6.

76. Ganassali $\mathrm{S}$. The influence of the design of web survey questionnaires on the quality of responses. Surv Res Method. 2008;2:21-32.

77. Brenner PS, DeLamater J. Lies, damned lies, amd survey reports? Identity as a cause of measurement bias. Soc Psychol Q. 2016;79:333-54. https://doi.org/10.1177/0190272516628298.

78. Olsen K, Peytchev A. Effect of interviewer experience on interview pace and interviewer attitudes. Public Opin Q. 2007;71:273-86.

79. Holbrook AL, Green MC, Krosnick JA. Telephone versus faceto-face interviewinig of national probability samples with long questionnaires. Public Opin Q. 2003;67:79-125.

Publisher's Note Springer Nature remains neutral with regard to jurisdictional claims in published maps and institutional affiliations.

Joe Hollinghurst $\mathrm{PhD}$

David G. Smithard MD 